\title{
Polyethylene glycol 8000+ citrate salts aqueous two-phase systems: Relative hydrophobicity of the equilibrium phases
}

\author{
Sara C. Silvério ${ }^{a, b}$, Jesús Gracia ${ }^{a}$, José A. Teixeira ${ }^{b}$, Eugénia A. Macedo ${ }^{a, *}$ \\ a LSRE-Laboratory of Separation and Reaction Engineering, Associate Laboratory LSRE/LCM, Department of Chemical Engineering, Faculty of Engineering, \\ University of Porto, Rua Dr Roberto Frias s/n, Porto 4200-465, Portugal \\ ${ }^{\mathrm{b}}$ CEB-Centre of Biological Engineering, University of Minho, Campus de Gualtar, Braga 4710-057, Portugal
}

\section{A R T I C L E I N F O}

\section{Article history:}

Received 3 May 2015

Received in revised form 12 July 2015

Accepted 13 July 2015

Available online 20 July 2015

\section{Keywords:}

Aqueous two-phase system

Polymer-salt

PEG

Citrate

Gibbs free energy of transfer

Hydrophobicity

\begin{abstract}
A B S T R A C T
The Gibbs free energy of transfer of a methylene group, $\Delta G^{*}\left(\mathrm{CH}_{2}\right)$, is reported as a measure of the relative hydrophobicity of the equilibrium phases. Furthermore, $\Delta G^{*}\left(\mathrm{CH}_{2}\right)$ is a characteristic parameter of each tie-line, and for that reason can be used for comparing different tie-lines of a given aqueous two-phase system (ATPS) or even to establish comparisons among different ATPSs. In this work, the partition coefficients of a series of four dinitrophenylated-amino acids were experimentally determined, at $23^{\circ} \mathrm{C}$, in five different tie-lines of PEG8000-(sodium or potassium) citrate ATPSs. $\Delta G^{*}\left(\mathrm{CH}_{2}\right)$ values were calculated from the partition coefficients and used to evaluate the relative hydrophobicity of the equilibrium phases. PEG8000-potassium citrate ATPSs presented larger relative hydrophobicity than PEG8000-sodium citrate ATPSs. Furthermore, the results obtained indicated that the PEG-rich phase (top phase) has higher affinity to participate in hydrophobic hydration interactions than the salt-rich phase (bottom phase).
\end{abstract}

(c) 2015 Elsevier B.V. All rights reserved.

\section{Introduction}

Aqueous two-phase systems (ATPSs) are known since 1896, when Beijerinck reported the formation of turbid solutions after mixing aqueous solutions of gelatine and agar or gelatine and starch [1]. Later, Dobry and Boyer-Kawenoki studied the miscibility of a large number of polymers and concluded that incompatibility was frequently verified, which resulted in the formation of several polymer-polymer ATPSs [1]. However, only in the 50s, Albertsson showed the potential of ATPSs in the separation and purification of biological constituents. He also described the formation of ATPSs obtained when mixing an aqueous solution of a polymer with lowmolecular weight components, such as ammonium or magnesium sulfate. Furthermore, Albertsson observed that most of the systems were water based, and biomolecules were able to distribute unevenly between phases [1]. Based on this interesting feature, the importance and applicability of ATPSs have significantly increased. Nowadays ATPSs are considered a powerful extraction technique with application in the separation and recovery of several biological compounds such as enzymes [2], cells [3], virus [4], antibodies [5], DNA or RNA [6].

\footnotetext{
* Corresponding author. Tel.: +35122508 1653; fax: +35122508 1674

E-mail address: eamacedo@fe.up.pt (E.A. Macedo).
}

Since their discovery, many ATPSs have been described and characterized. ATPSs formed by two polymers or a polymer and a salt represent the conventional and most studied systems. However, other alternative biphasic systems have been proposed, such as polymer-surfactant [7], ionic liquid-salt [8] or surfactant-ionic liquid [9]. The different types of ATPSs available offer different features that can be explored to selectively separate biomolecules.

Understanding the factors that regulate biomolecule partitioning between the equilibrium phases is fundamental to achieve an effective separation and also to intensify and develop the use of ATPSs at industrial level. Although in the last decades several studies have been reported concerning this issue, there is still a lack of experimental data in this field. It is known that the selective distribution of substances between the equilibrium phases is a consequence of the interactions established between solutes and phase-forming constituents. For that reason, the distribution is governed by the environmental conditions (ATPS composition and properties) and the structural characteristics of solutes [10]. Hydrophobic interactions are among the different types of interactions involved in solute partitioning. This kind of interactions has been reported to play a key role on the stability, conformation and function of biomolecules, namely proteins or enzymes [11]. The 3D structures of water-soluble proteins are stabilized by the susceptibility of hydrophobic groups to get close to each other. For enzymes, maintenance of the 3D structure is fundamental to keep its catalytic activity. Consequently, studies to investigate 
and evaluate the hydrophobic character of the solvent media gain particular importance when working with these biomolecules. Experimentally, the relative hydrophobicity of the equilibrium phases can be achieved by means of the free energy of transfer of a suitable hydrophobic probe, such as the methylene group $\left(\mathrm{CH}_{2}\right)$, between the phases, $\Delta G^{*}\left(\mathrm{CH}_{2}\right)$. This approach uses the partition coefficients of homologous series of aliphatic solutes and was previously described in detail [12]. $\Delta G^{*}\left(\mathrm{CH}_{2}\right)$ is considered a measure of the relative hydrophobicity of equilibrium phases and can be useful to characterize the solvent media and also to establish comparisons between different ATPSs. Furthermore, $\Delta G^{*}\left(\mathrm{CH}_{2}\right)$ was successfully used as solvent descriptor in the partitioning of biomolecules [13]. The application of descriptors for the modeling of different properties, such as partition coefficients, deserves particular attention because it contributes for the understanding of partition phenomena in ATPSs.

During the last decades, $\Delta G^{*}\left(\mathrm{CH}_{2}\right)$ have been determined for different types of biphasic systems, including the traditional polymer-polymer and polymer-salt ATPSs and also biphasic systems composed by ionic liquids, organic solvents or surfactants (Table 1). Zaslavsky et al. [26] firstly used of the partition coefficients of homologous series of aliphatic alcohols, amines, fatty acids and $\mathrm{N}$-acetyl ethyl esters of amino acids with an aliphatic side-chain to determine the free energy of transfer of a methylene group from aqueous to organic phase in several water-organic solvent biphasic systems (Table 1). Later, Masimov et al. [28] studied the relative hydrophobicity of $n$-octanol-aqueous polymer solution using the partitioning of a homologous series of dinitrophenylated-amino acids (DNP-amino acids). The $\Delta G^{*}\left(\mathrm{CH}_{2}\right)$ was also determined in micellar systems using different surfactants [27]. For example, Vitha and Carr [27] used homologous series of different solutes (phenylalkanols, alkylphenones, alkylbenzenes, nitroaliphatics and 4-alkylanilines) to determine the free energy of transfer of a methylene from a buffer solution to micelles of sodium dodecyl sulfate (SDS), sodium decyl sulfate (SDecS) and sodium octyl sulfate (SOS) (Table 1). For the traditional ATPSs (polymer-polymer and polymer-salt), several works reporting the study of the relative hydrophobicity can be found in the literature (Table 1$)$. The $\Delta G^{*}\left(\mathrm{CH}_{2}\right)$ for polymer-polymer ATPSs containing different buffers and $\mathrm{NaCl}$ as additive was determined using homologous series of DNP-amino acids [12,13] and aliphatic alcohols [14]. For polymer-salt ATPSs, the relative hydrophobicity was studied in biphasic systems of the type (PEG or UCON)-salt using the same homologous series of DNP-amino acids [16-20] or aliphatic alcohols [15]. Furthermore, the effect of different concentrations of salt additives $\left(\mathrm{NaCl}, \mathrm{NaSCN}, \mathrm{NaClO}_{4}\right.$ and $\left.\mathrm{NaH}_{2} \mathrm{PO}_{4}\right)$ was investigated in PEG8000- $\mathrm{Na}_{2} \mathrm{SO}_{4}$ ATPSs [19,20], showing that $\Delta G^{*}\left(\mathrm{CH}_{2}\right)$ become more negative when the concentration of the salt additive increases. More recently, the same approach to determine the $\Delta G^{*}\left(\mathrm{CH}_{2}\right)$ using homologous series of DNP-amino acids or aliphatic acids, was successfully applied to biphasic systems containing ionic liquids [21-25].

In this work, the partition coefficients of a homologous series of DNP-amino acids (DNP-glycine, DNP-alanine, DNP-valine and DNP-leucine) were used to determine the $\Delta G^{*}\left(\mathrm{CH}_{2}\right)$ in five tie-lines of PEG8000-(sodium or potassium) citrate ATPSs and to conclude about the relative hidrophobicity of the equilibrium phases. As far as we know, this is the first study reporting the $\Delta G^{*}\left(\mathrm{CH}_{2}\right)$ of ATPSs composed by PEG and citrate salts.

\section{Experimental}

\subsection{Materials}

Poly(ethylene glycol), PEG (average molecular weight 8000) and sodium citrate tribasic dehydrate $\left(\mathrm{Na}_{3} \mathrm{C}_{6} \mathrm{H}_{5} \mathrm{O}_{7} \cdot 2 \mathrm{H}_{2} \mathrm{O}\right.$, ACS reagent, $\geq 99.0 \%)$ were obtained from Sigma. Potassium citrate tribasic monohydrate $\left(\mathrm{K}_{3} \mathrm{C}_{6} \mathrm{H}_{5} \mathrm{O}_{7} \cdot \mathrm{H}_{2} \mathrm{O}\right.$, purum p.a., $\left.\geq 99.0 \%\right)$ was purchased from Fluka Analytical. Stock solutions of each chemical were prepared in deionized water (ca. $50 \mathrm{wt} \%$ for PEG, $40 \mathrm{wt} \%$ for sodium and potassium citrate) and all concentrations were obtained gravimetrically after evaporation on heating plate (Stuart hotplate SB300) for salts or after lyophilization (Scan Vac, model CoolSafe 55-4) for PEG.

Dinitrophenylated amino acids (DNP-amino acids) were supplied by Sigma ( $N$-(2,4-dinitrophenyl)glycine, $\geq 99 \%$ and $(\mathrm{N}$ (2,4-dinitrophenyl)-DL- $n$-valine, $\geq 97 \%)$, and Research Organics ( $N$-(2,4-dinitrophenyl)-L-alanine, $\geq 97 \%$ and $N$-(2,4-dinitrophenyl)DL- $n$-leucine, $\geq 97 \%)$. Stock solutions of the four DNP-amino acids were prepared in deionized water $(0.2 \mathrm{wt} \%)$.

All products were used as received without further purification. Deionized water was used for all diluting purposes. All weighing was carried out on an Adam Equipment balance model AAA250L, precise to within $\pm 0.2 \mathrm{mg}$.

\subsection{Methods}

The procedure to obtain the partition coefficients of the DNPamino acids has been explained in detail before [16-19]. Different amounts of a given DNP-amino acid stock solution (from 0 to $100 \mathrm{mg}$ ) were added to six replicates of a certain ATPS with the same feed composition. The corresponding amount of water (from 100 to $0 \mathrm{mg}$ ) was added to keep all compositions constant except for the DNP-amino acids. The components of the six replicates were vigorously vortex-mixed (VWR, model VV3) during 2 min and phase separation was accelerated by centrifugation (minispin, Eppendorf) at $10^{4}$ r.p.m. for $15 \mathrm{~min}$. Then, samples of each phase were withdrawn, conveniently diluted with water, and their absorbance at $362 \mathrm{~nm}$ was measured in a UV-vis spectrophotometer (Thermo electron corporation, UV1). Partition coefficients $(K)$ for the four DNP-amino-acids were determined as the slope of the straight line obtained when comparing the amino acid absorbance in the top phase against that in the bottom phase, both corrected with the corresponding dilution factors, DF (final volume divided by the initial volume):

$$
K=\frac{\mathrm{Abs}(\text { top }) \mathrm{DF}_{\text {top }}}{\mathrm{Abs}(\text { bottom }) \mathrm{DF}_{\text {bottom }}}
$$

\section{Results and discussion}

The partition coefficients of DNP-glycine, DNP-alanine, DNPvaline and DNP-leucine were determined in five different tie-lines of PEG-(sodium or potassium) citrate salt ATPSs previously characterized [29]. Information about the tie-line length (TLL) and feed composition as well as the corresponding partition coefficients obtained for each tie-line are presented in Table 2. Straight lines were obtained for each DNP-amino acid when the absorbance in the top phase was plotted against the absorbance in the bottom phase, for the six replicates prepared with different solute concentration. The experimental partition coefficients, $K$, were calculated after linear regression from the slope of the lines:

$\operatorname{Abs}($ top $)=K \operatorname{Abs}($ bottom $)+b$

and conveniently corrected using the corresponding dilution factors used in each phase. In Eq. (2), $b$ corresponds to the intercept and it was found to be almost zero (average $b=0.002$ ). The straight lines obtained for each DNP-amino acid have coefficients of determination $r^{2} \geq 0.991$ with average $r^{2}=0.997$. This confirms that partition coefficients experimentally determined are independent from the solute concentration. Furthermore, it is ensured that there are no 
Table 1

Gibbs free energy of transfer of a methylene group between the equilibrium phases in several biphasic systems.

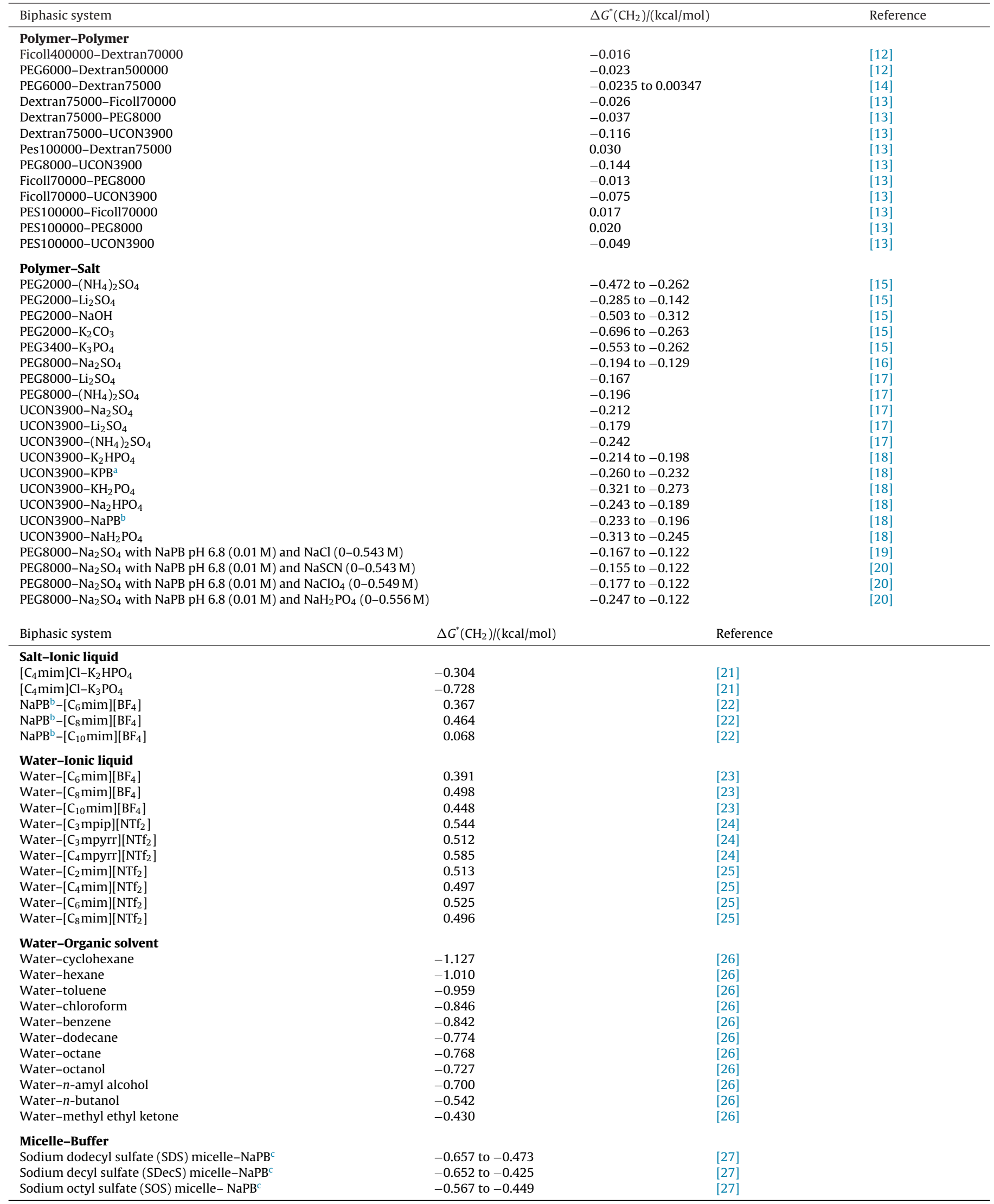

a KPB-Potassium phosphate buffer $\mathrm{pH} 7.0$

b NaPB-Sodium phosphate buffer pH 7.0.

c NaPB-Sodium phosphate buffer pH 6.8. 
Table 2

Partition coefficients experimental obtained for the for DNP-amino acids at $23^{\circ} \mathrm{C}$.

\begin{tabular}{|c|c|c|c|c|c|c|c|}
\hline \multirow[t]{2}{*}{ Tie-line } & \multirow[t]{2}{*}{$\mathrm{TLL}^{\mathrm{a}}$} & \multicolumn{6}{|c|}{ Composition $(\% \mathrm{w} / \mathrm{w})^{\mathrm{a}} K$} \\
\hline & & Salt & Polymer & DNP-Glycine & DNP-Alanine & DNP-Valine & DNP-Leucine \\
\hline \multicolumn{8}{|c|}{ PEG8000-Sodium citrate } \\
\hline 1 & 0.199 & 10.27 & 10.91 & $4.608 \pm 0.045$ & $4.984 \pm 0.059$ & $7.289 \pm 0.112$ & $9.368 \pm 0.068$ \\
\hline 2 & 0.266 & 11.05 & 12.01 & $6.128 \pm 0.231$ & $7.103 \pm 0.230$ & $11.17 \pm 0.09$ & $14.05 \pm 0.37$ \\
\hline 3 & 0.320 & 12.06 & 13.05 & $7.560 \pm 0.131$ & $9.720 \pm 0.371$ & $15.21 \pm 0.36$ & $20.05 \pm 0.60$ \\
\hline 4 & 0.361 & 12.99 & 13.97 & $10.66 \pm 0.27$ & $13.68 \pm 0.32$ & $22.41 \pm 0.67$ & $30.34 \pm 0.33$ \\
\hline 5 & 0.395 & 13.82 & 14.98 & $13.03 \pm 0.38$ & $17.59 \pm 0.33$ & $29.6 \pm 1.5$ & $41.2 \pm 1.9$ \\
\hline \multicolumn{8}{|c|}{ PEG8000-Potassium citrate } \\
\hline 1 & 0.207 & 12.55 & 11.88 & $3.428 \pm 0.131$ & $4.136 \pm 0.131$ & $6.060 \pm 0.130$ & $7.697 \pm 0.084$ \\
\hline 2 & 0.310 & 14.50 & 12.95 & $6.422 \pm 0.160$ & $7.684 \pm 0.072$ & $13.27 \pm 0.63$ & $17.60 \pm 0.34$ \\
\hline 3 & 0.381 & 16.45 & 14.04 & $9.456 \pm 0.222$ & $11.84 \pm 0.23$ & $20.24 \pm 0.90$ & $30.47 \pm 0.98$ \\
\hline 4 & 0.443 & 18.42 & 15.02 & $13.53 \pm 0.05$ & $18.82 \pm 0.55$ & $35.2 \pm 1.2$ & $50.36 \pm 0.74$ \\
\hline 5 & 0.493 & 20.36 & 15.93 & $21.74 \pm 0.68$ & $30.77 \pm 0.78$ & $60.8 \pm 1.5$ & $90.6 \pm 4.6$ \\
\hline
\end{tabular}

a Obtained from reference [29].
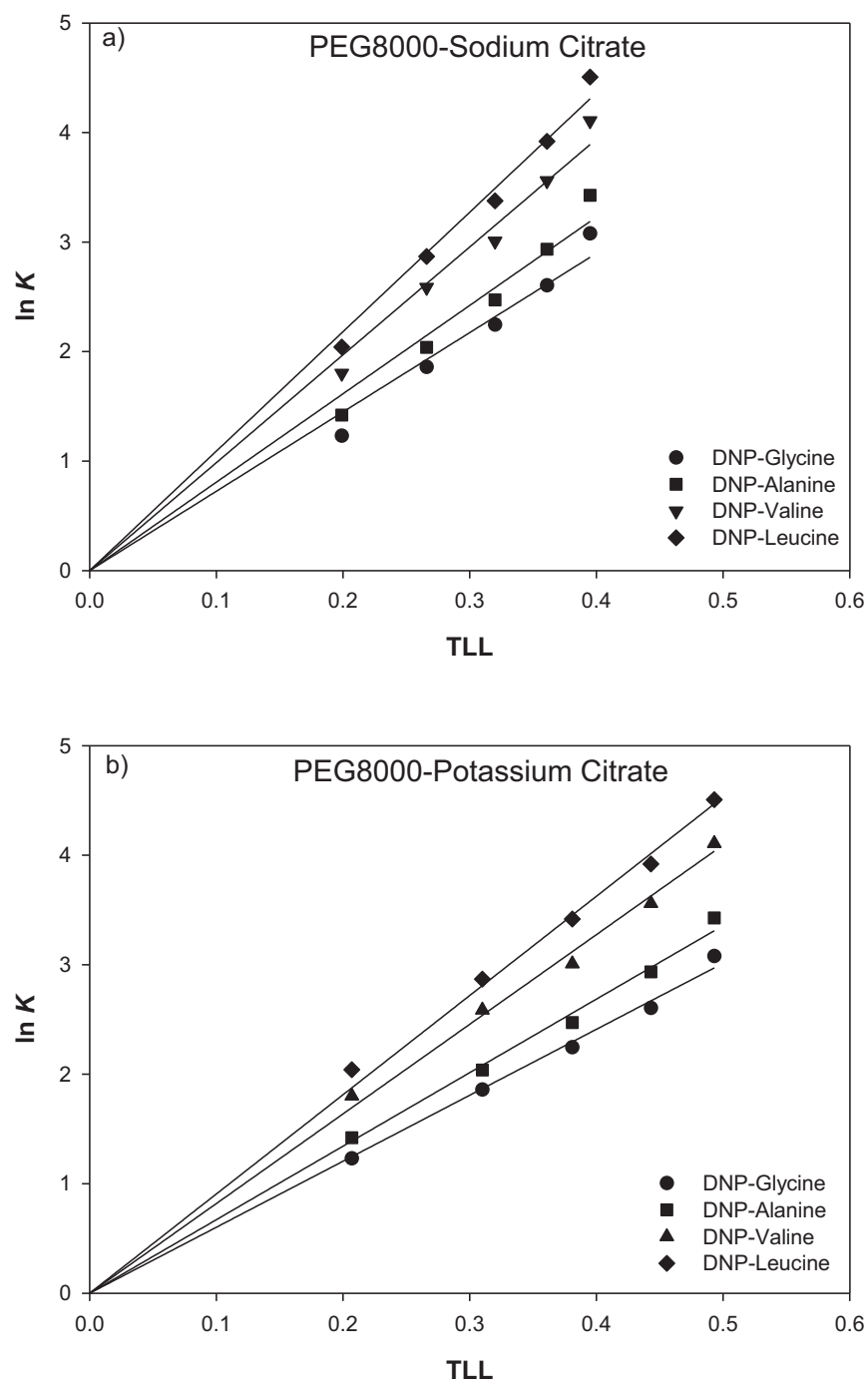

Fig. 1. Logarithms of the partition coefficients of the DNP-amino acids as a function of the TLL for: (a) PEG8000-sodium citrate and (b) PEG8000-potassium citrate ATPSs.

interactions affecting the solute partition behaviour, like solute self-association or dissociation [12].

When the logarithm of the partition coefficients of each DNP-amino acid, $\ln K$, is plotted as a function of the TLL of the PEGcitrate ATPSs, a linear representation is obtained (Fig. 1). A similar tendency was previously observed for other polymer-salt ATPSs $[16,18]$. The TLL is considered a measurement of the differences in phase composition and it becomes larger as the biphasic system moves into the heterogeneous region. The linearity found in Fig. 1 indicates that the partition coefficient for a given DNP-amino acid increases with the TLL. Therefore, the partition of the DNP-amino acid occurs more preferentially to top (PEG-rich) phase as the biphasic system moves into the heterogeneous region. Furthermore, for a given tie-line, the partition coefficient of the DNP-amino acids followed the trend: $K_{\text {leucine }}>K_{\text {valine }}>K_{\text {alanine }}>K_{\text {glycine. }}$ This indicates that the longer the side chain of the DNP-amino acid, the higher its affinity for the top (PEG-rich) phase.

The representations of the logarithms of the partition coefficients as function of the average number of methylene groups present in the aliphatic side chain of the homologous DNP-amino acids, $n\left(\mathrm{CH}_{2}\right)$ are shown in Fig. 2. For both ATPSs, a linear representation is obtained, nevertheless it is important to highlight that the $n\left(\mathrm{CH}_{2}\right)$ used in Fig. 2 are adjusted values and they are different from the real alkyl chain length of the DNP-amino acids $(0,1$, 3 and 4). The adjustment of the $n\left(\mathrm{CH}_{2}\right)$ values for each amino acid was previously reported and a detailed explanation can be found in the literature [12]. The $n\left(\mathrm{CH}_{2}\right)$ used in this work were optimized by Zaslavsky [12] and their suitability for polymer-salt ATPSs has been shown before $[25,26]$.

Applying the group-contribution concept, the linearity observed in Fig. 2 can be described as:

$\ln K_{\mathrm{DNP}-\mathrm{AA}}=\mathrm{C}+\mathrm{En}\left(\mathrm{CH}_{2}\right)$

where, $K_{\mathrm{DNP}-\mathrm{AA}}$ is the partition coefficient determined for each DNPamino acid and $n\left(\mathrm{CH}_{2}\right)$ is the equivalent number of methylene groups present in the aliphatic side-chain. $E$ and $C$ are constants which represent the slope and intercept of the line, respectively. Nevertheless, a physical meaning can be attributed to these constants: $E$ represents the contribution of each $\mathrm{CH}_{2}$ to the partition coefficient while $C$ denotes the contribution of the non-alkyl part of the DNP-amino acid structure to the partition coefficient [12]. The values obtained for the constants $E$ and $C$ in each tie-line are indicated in Table 3, together with the corresponding coefficients of determination. It can be seen that both $E$ and $C$ are dependent on the composition of the biphasic systems.

The standard free energy of transfer $\left(\Delta G^{*}\right)$ of a given solute $i$ between the coexisting phases is related with the solute partition coefficient and can be defined as:

$\Delta G^{*}=-R T \ln K_{i}$

where, $R$ is the universal gas constant and $T$ is the absolute temperature (in Kelvin). Consequently, for the standard Gibbs free energy 
Table 3

$\Delta G^{*}\left(\mathrm{CH}_{2}\right)$ values and parameters $C$ and $E$ obtained for the five tie-lines of PEG8000-(sodium or potassium) citrate ATPSs.

\begin{tabular}{|c|c|c|c|c|}
\hline Tie-line & C & $E$ & $r^{2}$ & $\Delta G^{*}\left(\mathrm{CH}_{2}\right) /(\mathrm{Kcal} / \mathrm{mol})$ \\
\hline \multicolumn{5}{|c|}{ PEG8000-Sodium citrate } \\
\hline 1 & $1.323 \pm 0.034$ & $0.245 \pm 0.014$ & 0.993 & -0.144 \\
\hline 2 & $1.607 \pm 0.047$ & $0.284 \pm 0.019$ & 0.991 & -0.167 \\
\hline 3 & $1.824 \pm 0.054$ & $0.322 \pm 0.022$ & 0.991 & -0.189 \\
\hline 4 & $2.142 \pm 0.050$ & $0.348 \pm 0.021$ & 0.993 & -0.204 \\
\hline 5 & $2.334 \pm 0.062$ & $0.379 \pm 0.026$ & 0.991 & -0.223 \\
\hline \multicolumn{5}{|c|}{ PEG8000-Potassium citrate } \\
\hline 1 & $1.055 \pm 0.035$ & $0.269 \pm 0.015$ & 0.994 & -0.158 \\
\hline 2 & $1.609 \pm 0.055$ & $0.345 \pm 0.023$ & 0.992 & -0.203 \\
\hline 3 & $1.962 \pm 0.011$ & $0.390 \pm 0.005$ & 0.999 & -0.229 \\
\hline 4 & $2.332 \pm 0.077$ & $0.437 \pm 0.032$ & 0.990 & -0.257 \\
\hline 5 & $2.777 \pm 0.077$ & $0.475 \pm 0.032$ & 0.992 & -0.279 \\
\hline
\end{tabular}
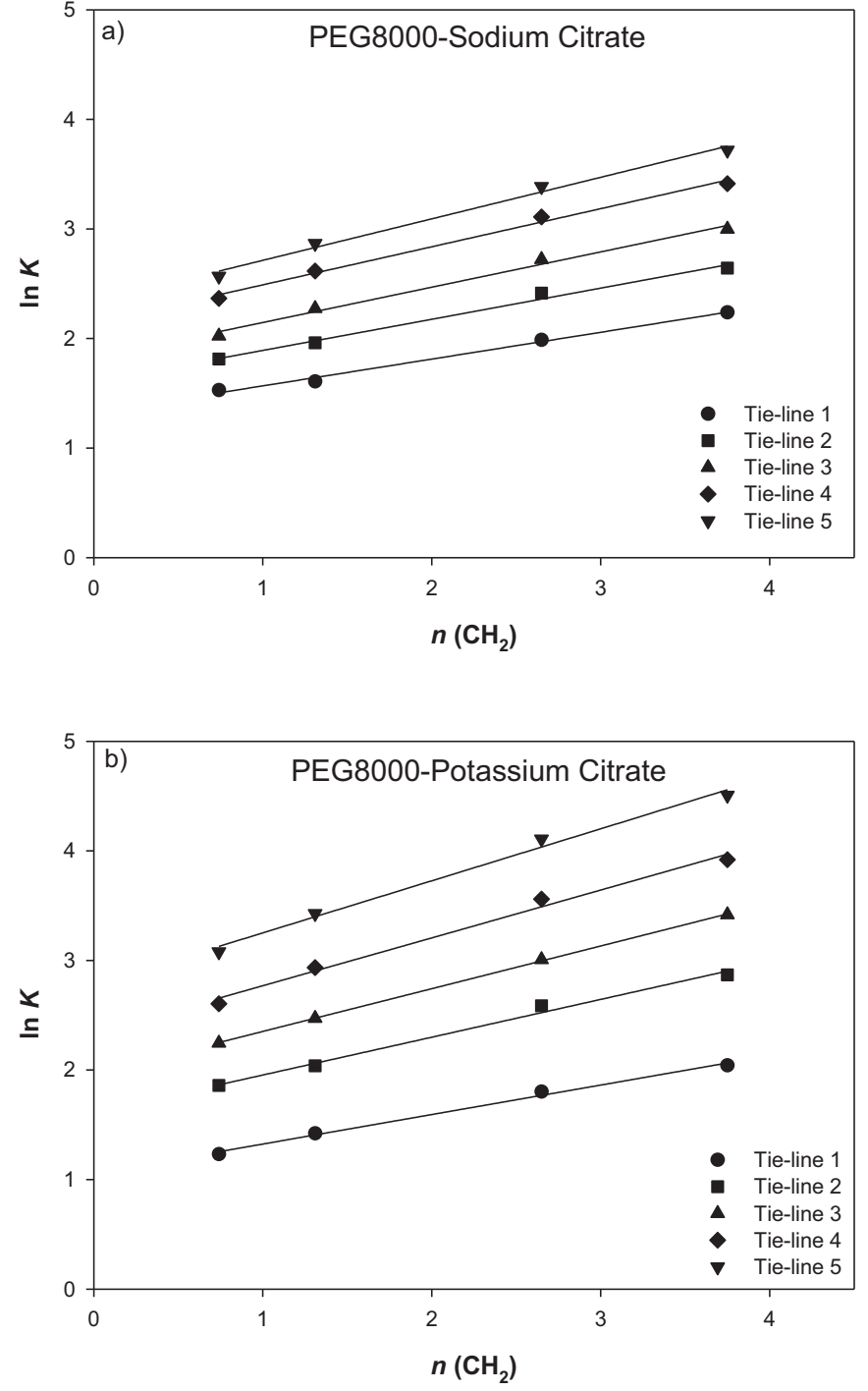

Fig. 2. Logarithm of the partition coefficients of the DNP-amino acids as a function of the average number of methylene groups present in the aliphatic side chain for: (a) PEG8000-sodium citrate and (b) PEG8000-potassium citrate ATPSs.

of transfer of a methylene group, $\Delta G^{*}\left(\mathrm{CH}_{2}\right)$, and considering Eq. (3), the following expression is obtained:

$$
\Delta G^{*}\left(\mathrm{CH}_{2}\right)=-R T E
$$

The free energy of transfer of a methylene group determined for each tie-line of the PEG-citrate salt ATPSs using the corresponding $E$ value are indicated in Table 3. The $\Delta G^{*}\left(\mathrm{CH}_{2}\right)$ values found range from -0.144 to $-0.279 \mathrm{kcal} / \mathrm{mol}$, which are in agreement with the values of $\Delta G^{*}\left(\mathrm{CH}_{2}\right)$ reported in the literature for polymer-salt ATPSs $(-0.1$ to $-0.7 \mathrm{kcal} / \mathrm{mol}$, see Table 1). Comparatively, polymer-polymer ATPSs present less negative values of free energy of transfer of a methylene group (Table 1). In general, for these ATPSs the $\Delta G^{*}\left(\mathrm{CH}_{2}\right)$ values do not surpass $-0.1 \mathrm{kcal} / \mathrm{mol}$, essentially because equilibrium phases are more similar [14]. The exceptions in Table 1 are the PEG8000-UCON3900 and Dextran75000-UCON3900 ATPSs which provided $\Delta G^{*}\left(\mathrm{CH}_{2}\right)<-0.1 \mathrm{kcal} / \mathrm{mol}$. Furthermore, the $\Delta G^{*}\left(\mathrm{CH}_{2}\right)$ obtained for tie-line 1 of PEG8000- $\mathrm{Na}_{3} \mathrm{C}_{6} \mathrm{H}_{5} \mathrm{O}_{7}$ is identical to that found for the biphasic system composed by PEG8000 and UCON3900, a random copolymer with of 50\% ethylene oxide and $50 \%$ propylene oxide. This means that despite the differences in phase composition, the affinity of the equilibrium phases for the methylene group is similar in both ATPSs.

According to Table 3 , the most negative values of $\Delta G^{*}\left(\mathrm{CH}_{2}\right)$ were obtained for the biphasic systems composed by potassium citrate. Therefore, PEG8000-potassium citrate ATPSs have larger relative hydrophobicity and consequently a more efficient biphasic separation, with lower cross-contamination between the equilibrium phases. It is not possible to establish a direct comparison between PEG8000- $\mathrm{Na}_{3} \mathrm{C}_{6} \mathrm{H}_{5} \mathrm{O}_{7}$ and PEG8000- $\mathrm{K}_{3} \mathrm{C}_{6} \mathrm{H}_{5} \mathrm{O}_{7}$ ATPSs regarding the $\Delta G^{*}\left(\mathrm{CH}_{2}\right)$ value because the feed composition and also the compositions of the equilibrium phases are different. However, we can perform a practical evaluation by comparing the tie-lines of both ATPSs with similar TLL. Using this approach, we found that $\Delta G^{*}\left(\mathrm{CH}_{2}\right)$ obtained for PEG8000- $\mathrm{K}_{3} \mathrm{C}_{6} \mathrm{H}_{5} \mathrm{O}_{7}$ ATPSs are approximately 1.1 -fold more negative than those found for

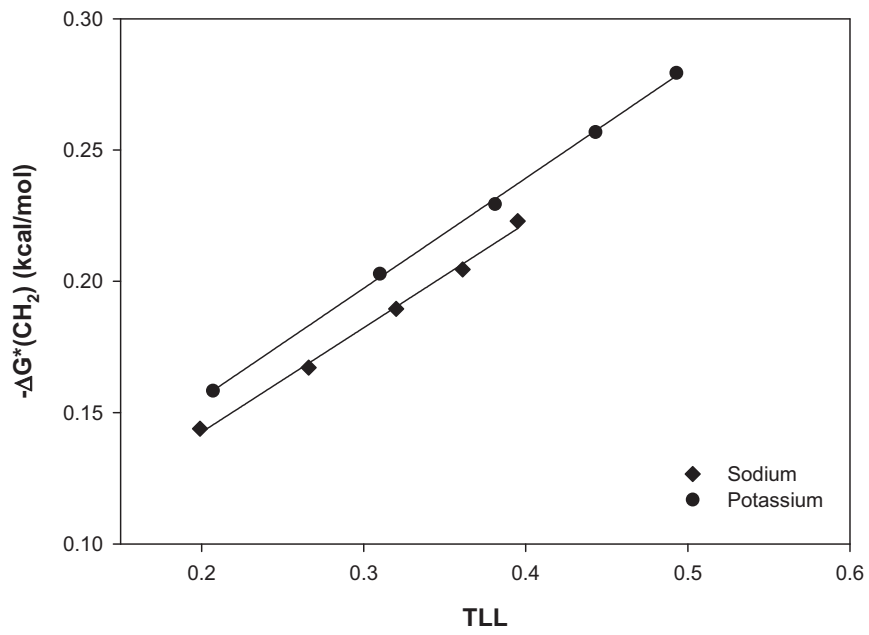

Fig. 3. $\Delta G^{*}\left(\mathrm{CH}_{2}\right)$ values as a function of the TLL for the PEG8000-(sodium or potassium) citrate ATPSs studied. 


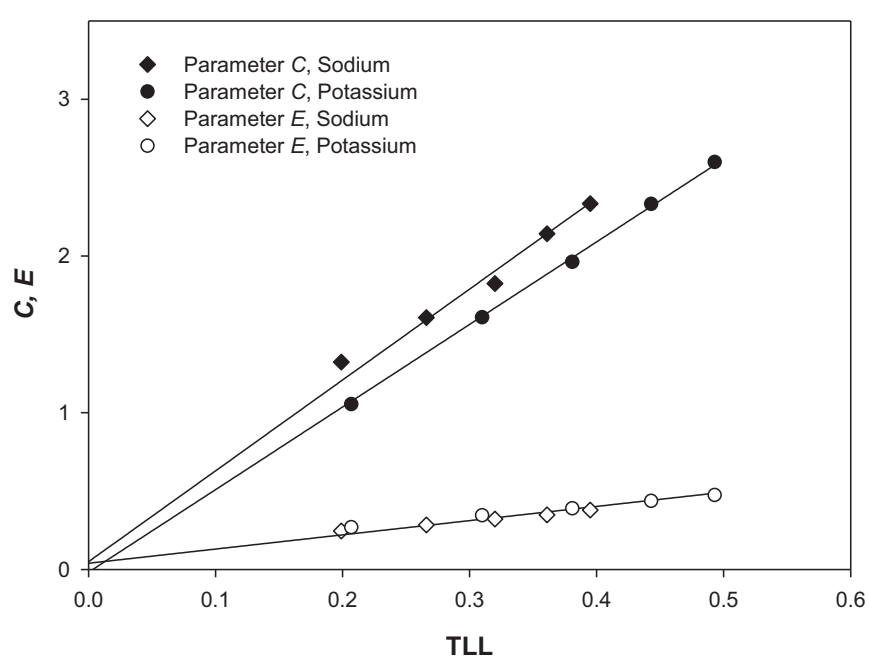

Fig. 4. Parameters $E$ and $C$ as a function of the TLL for the PEG8000-(sodium or potassium) citrate ATPSs studied.

PEG8000- $\mathrm{Na}_{3} \mathrm{C}_{6} \mathrm{H}_{5} \mathrm{O}_{7}$ ATPSs, as can be seen in Fig. 3. A similar representation would be obtained if the $\Delta G^{*}\left(\mathrm{CH}_{2}\right)$ value were represented as a function of the difference in PEG or salt concentration between the coexisting phases ( $\triangle$ PEG or $\Delta$ salt) because all of these parameters reflect the degree of phase divergence [15].

The representation in Fig. 4 reflects the effect of phase composition in the parameters $C$ and $E$. For $C$ parameter, which represents the contribution of the non-alkyl part of the DNP-amino acid structure to the partition coefficient, it is possible to identify two tendencies: one corresponding to sodium citrate and the other one corresponding to potassium citrate. Therefore, $C$ parameter seems to be affected by the type of cation used to prepare the biphasic system. On the contrary, the $E$ parameter is not dependent on the cation present in the system. This behaviour is in agreement with the literature, $C$ parameter was previously reported to be dependent on both the salt composition and PEG molecular weight $[18,30]$.

\section{Conclusions}

$\Delta G^{*}\left(\mathrm{CH}_{2}\right)$ values calculated from the partition coefficients of four DNP-amino acids in different tie-lines of PEG8000-(sodium or potassium) citrate ATPSs were used to obtain a measure of the relative hydrophobicity of the equilibrium phases. PEG-salt ATPSs composed by potassium citrate presented larger relative hydrophobicity, which indicates a more efficient phase splitting, with lower cross-contamination between the equilibrium phases.

The $\Delta G^{*}\left(\mathrm{CH}_{2}\right)$ values reported in the present work are in agreement with the values reported in the literature for different polymer-salt ATPSs. The results obtained indicate that the PEG-rich phase (top phase) has greater affinity to participate in hydrophobic hydration interactions than the salt-rich phase (bottom phase).

\section{Acknowledgements}

This work was partially supported by FCT/MEC and FEDER under Programe PT2020 (Project UID/EQU/50020/2013), and co-financed by QREN, ON2 and FEDER (Projects NORTE-07-0162FEDER-000050 and NORTE-07-0124-FEDER-0000011), for which the authors are thankful. SCS also acknowledges her post-doc grant (SFRH/BPD/88584/2012) from FCT.

\section{References}

[1] P.A. Albertsson, Partition of Cell Particles and Macromolecules, 3rd ed., John Willey \& Sons, New York, 1986.

[2] S. Moreira, S.C. Silvério, E.A. Macedo, A.M.F. Milagres, J.A. Teixeira, S.I. Mussatto, J. Chromatogr. A 1321 (2013) 14-20.

[3] M. González-González, M. Rito-Palomares, O.M. Quintero, Biotechnol. Prog. 30 (2014) 700-707.

[4] P. Guo, Y. El-Gohary, K. Prasadan, C. Shiota, X. Xiao, J. Wiersch, J. Paredes, S. Tulachan, G.K. Gittes, J. Virol. Methods 183 (2012) 139-146.

[5] J. Muendges, I. Stark, S. Mohammad, A. Górak, T. Zeiner, Fluid Phase Equilib. 385 (2015) 227-236.

[6] F. Luechau, T.C. Ling, A. Lyddiatt, Process Biochem. 45 (2010) 1432-1436.

[7] Y. Liu, Z. Wu, Y. Zhao, Thermochim. Acta 602 (2015) 78-86.

[8] X. Tang, J. Han, Y. Hu, Y. Wang, Y. Lu, T. Chen, L. Ni, Fluid Phase Equilib. 383 (2014) 100-107.

[9] X. Wang, X. Wei, J. Liu, J. Liu, D. Sun, P. Du, A. Ping, Fluid Phase Equilib. 347 (2013) 1-7.

[10] A. Fiechter (Ed.), Bioseparation-Advances in Biochemical Engineering/Biotechnology, 47, Springer - Verlag Berlin, Heidelberg, 1992, pp. 89-135.

[11] G.D. Rose, R. Wolfenden, Annu. Rev. Biophys. Biomol. 22 (1993) 381-415.

[12] B.Y. Zaslavsky, Aqueous Two-Phase Partitioning: Physical Chemistry and Bioanalytical Applications, Marcel Dekker, New York, 1994.

[13] P.P. Madeira, J.A. Teixeira, E.A. Macedo, L.M. Mikheeva, B.Y. Zaslavsky, J. Chromatogr. A 1185 (2008) 58-92.

[14] M.L. Moody, H.D. Willauer, S.T. Griffin, J.G. Huddleston, R.D. Rogers, Ind. Eng Chem. Res. 44 (2005) 3749-3760.

[15] H.D. Willauer, J.G. Huddleston, R.D. Rogers, Ind. Eng. Chem. Res. 41 (2002) 2591-2601.

[16] O. Rodríguez, S.C. Silvério, P.P. Madeira, J.A. Teixeira, E.A. Macedo, Ind. Eng. Chem. Res. 46 (2007) 8199-8204.

[17] S.C. Silvério, P.P. Madeira, O. Rodríguez, J.A. Teixeira, E.A. Madeira, J. Chem. Eng. Data 53 (2008) 1622-1625.

[18] S.C. Silvério, O. Rodríguez, J.A. Teixeira, E.A. Macedo, J. Chem. Thermodyn. 42 (2010) 1063-1069.

[19] L.A. Ferreira, P. Parpot, J.A. Teixeira, L.M. Mikheeva, B.Y. Zaslavsky, J. Chromatogr. A 1220 (2012) 14-20.

[20] N.R. da Silva, L.A. Ferreira, L.M. Mikheeva, J.A. Teixeira, B.Y. Zaslavsky, J. Chromatogr. A 1337 (2014) 3-8.

[21] N.J. Bridges, K.E. Gutowski, R.D. Rogers, Green Chem. 9 (2007) 177-183.

[22] O. Rodríguez, P.P. Madeira, E.A. Macedo, Ind. Eng. Chem. Res. 47 (2008) 5165-5168.

[23] F.M. Maia, O. Rodríguez, E.A. Macedo, J. Chem. Thermodyn. 48 (2012) 221-228

[24] F.M. Maia, O. Rodríguez, E.A. Macedo, Ind. Eng. Chem. Res. 51 (2012) 8061-8068.

[25] F.M. Maia, O. Rodríguez, E.A. Macedo, J. Chem. Eng. Data 58 (2013) 1565-1570.

[26] B.Y. Zaslavsky, L.M. Mikheeva, S.V. Rodozhin, J. Chromatogr. 216 (1981) 103-113.

[27] M.F. Vitha, P.W. Carr, Sep. Purif. Technol. 33 (1998) 2075-2100.

[28] A.A. Masimov, B.Y. Zaslavsky, A.A. Gasanov, S.V. Rogozhin, J. Chromatogr. 284 (1984) 337-348

[29] S.C. Silvério, A. Wegrzyn A, E. Lladosa, O. Rodríguez, E.A. Macedo, J. Chem. Eng. Data 57 (2012) 1203-1208.

[30] B.Y. Zaslavsky, N.D. Gulaeva, S. Djafarov, E.A. Masimov, L.M. Miheeva, J. Colloid Interface Sci. 137 (1990) 147-156. 